\title{
Evidence That the Anti-Inflammatory Effect of Rubiadin-1-methyl Ether Has an Immunomodulatory Context
}

\author{
Eduarda Talita Bramorski Mohr, ${ }^{1}$ Marcus Vinicius Pereira dos Santos Nascimento, ${ }^{1}$ \\ Júlia Salvan da Rosa, ${ }^{1}$ Guilherme Nicácio Vieira, ${ }^{1}$ Iara Fabricia Kretzer $\left(\mathbb{D},{ }^{1}\right.$ \\ Louis Pergaud Sandjo $\mathbb{D}^{2},{ }^{2}$ and Eduardo Monguilhott Dalmarco $\mathbb{1}^{1}$ \\ ${ }^{1}$ Department of Clinical Analysis, Center of Health Sciences, Federal University of Santa Catarina, Campus Universitário-Trindade, \\ 88040-970 Florianópolis, SC, Brazil \\ ${ }^{2}$ Department of Pharmaceutical Sciences, Center of Health Sciences, Federal University of Santa Catarina, Campus Universitário- \\ Trindade, 88040-970 Florianópolis, SC, Brazil
}

Correspondence should be addressed to Eduardo Monguilhott Dalmarco; eduardo.dalmarco@ufsc.br

Received 3 June 2019; Accepted 4 October 2019; Published 3 November 2019

Academic Editor: Sandra Helena Penha Oliveira

Copyright (c) 2019 Eduarda Talita Bramorski Mohr et al. This is an open access article distributed under the Creative Commons Attribution License, which permits unrestricted use, distribution, and reproduction in any medium, provided the original work is properly cited.

Background. In spite of the latest therapeutic developments, no effective treatments for handling critical conditions such as acute lung injuries have yet been found. Such conditions, which may result from lung infections, sepsis, multiple trauma, or shock, represent a significant challenge in intensive care medicine. Seeking ways to better deal with this challenge, the scientific community has recently devoted much attention to small molecules derived from natural products with anti-inflammatory and immunomodulatory effects. Aims. In this context, we investigated the anti-inflammatory effect of Rubiadin-1-methyl ether isolated from Pentas schimperi, using an in vitro model of RAW 264.7 macrophages induced by LPS and an in vivo model of acute lung injury (ALI) induced by LPS. Methods. The macrophages were pretreated with the compound and induced by LPS $(1 \mu \mathrm{g} / \mathrm{mL})$. After $24 \mathrm{~h}$, using the supernatant, we evaluated the cytotoxicity, NOx, and IL-6, IL- $1 \beta$, and TNF- $\alpha$ levels, as well as the effect of the compound on macrophage apoptosis. Next, the compound was administered in mice with acute lung injury (ALI) induced by LPS $(5 \mathrm{mg} / \mathrm{kg})$, and the pro- and anti-inflammatory parameters were analyzed after $12 \mathrm{~h}$ using the bronchoalveolar lavage fluid (BALF). Results. Rubiadin-1-methyl ether was able to inhibit the pro-inflammatory parameters studied in the in vitro assays (NOx, IL-6, and IL-1 $\beta$ ) and, at the same time, increased the macrophage apoptosis rate. In the in vivo experiments, this compound was capable of decreasing leukocyte infiltration; fluid leakage; NOx; IL-6, IL-12p70, IFN- $\gamma$, TNF- $\alpha$, and MCP-1 levels; and MPO activity. In addition, Rubiadin-1-methyl ether increased the IL-10 levels in the bronchoalveolar lavage fluid (BALF). Conclusions. These findings support the evidence that Rubiadin-1-methyl ether has important anti-inflammatory activity, with evidence of an immunomodulatory effect.

\section{Introduction}

Anthraquinones are an important class of synthetic and natural compounds with a wide and diverse range of actions. In addition to their use as dyes, they present highly pharmacological diversity with proven laxative, anticancer, antiarrhythmic, antibacterial, antifungal, antiviral, and antiinflammatory activities [1]. The genus Pentas belongs to the Rubiaceae family. It is known for its anthraquinone compounds and is routinely used in traditional medicine, mainly in the African continent, to treat dysmenorrhea, headache, and pyrexia $[2,3]$. Rubiadin-1-methyl ether is an anthraquinone compound easily isolated from the Pentas species. However, there are a few reports that demonstrate its biological effects [4]. Thus, despite the anti-inflammation-proved effects of anthraquinones, we decided to evaluate this potential effect on Rubiadin-1-methyl ether compound $[4,5]$.

The inflammatory reaction is a defensive response against factors that disrupt host homeostasis. This phenomenon is modulated through a complex system of factors. After 
the initial trigger, there are production and release of protein-based and lipid mediators, which coordinate and increase the blood flow and permeability of the blood capillaries, inducing the movement of leukocytes to the initial stimulus [6]. Among the leukocytes involved, macrophages represent a pivotal role, due to their ability to recognize pathogen-associated molecular patterns (PAMPs) such as lipopolysaccharide (LPS), one of the main molecules responsible for the development of acute lung injury [7]. Despite recent therapeutic technologies, there is a lack of adequate treatment for this condition, which represents an important challenge in intensive care medicine. Recently, research has focused on small molecules derived from natural products with anti-inflammatory and immunomodulatory effects, since this condition is the result of an intricate and complex inflammatory response [8]. In this context, we evaluated the anti-inflammatory properties of Rubiadin-1methyl ether, investigating its effects on cytotoxicity; nitric oxide (NOx) inhibition; IL-6, IL- $1 \beta$, and TNF- $\alpha$ production; and the influence of this compound under macrophage apoptosis, using an in vitro model. We also performed an evaluation of Rubiadin-1-methyl ether on the leukocyte migration, fluid leakage, MPO activity, NOx, and pro- and anti-inflammatory cytokine (IL-6, IL-10, IL-12p70, MCP-1, INF- $\gamma$, and TNF- $\alpha$ ) production, using an in vivo model.

\section{Materials and Methods}

2.1. Compound. The compound was extracted and isolated by our research group from the roots of Pentas schimperi. Briefly, dried roots were used to extract Rubiadin-1-methyl ether in methanol $(3 \times 6 \mathrm{~L})$. This solution was conditioned at room temperature for 72 hours to produce a crude extract after filtration and vacuum evaporation. The extract was subjected to column chromatography to isolate Rubiadin1-methyl ether, according to the methodology already published [9] (Figure 1).

For the in vitro experiments, Rubiadin-1-methyl ether was dissolved in $1 \%$ dimethyl sulfoxide (DMSO), aliquoted, and stored at $-20^{\circ} \mathrm{C}$ until the moment of the experiments, when it was properly dissolved in cell medium. During the in vivo assays, the compound was dissolved in a solution of sterile saline $(0.9 \% \mathrm{NaCl})$, polysorbate- 20 (5\%, Tween-20), and dimethyl sulfoxide (5\%, DMSO). The solutions were prepared on the same days as the experiments.

2.2. Reagents and Drugs. The following drugs and reagents used were obtained from BD Biosciences (San Diego, California, USA): IL- $1 \beta$ ELISA kit; FITC annexin V apoptosis detection Kit I, cytometric bead array-CBA mouse inflammation kit, albumin (bovine serum), and Folin and Ciocalteu's phenol reagent; from BioTech (São Paulo, São Paulo, Brazil): hydrogen peroxide 30\%; from Gibco (Grand Island, New York, USA): Dulbecco's modified Eagle's medium (DMEM), fetal bovine serum (FBS), penicillin-streptomycin $(10,000 \mathrm{U} / \mathrm{mL})$, Versene ${ }^{\circledR}\left(2 \mathrm{~g}\right.$ EDTA, $\left.\mathrm{Na}_{4}\right)$, and Trypan blue dye; from LaborClin (Pinhais, Paraná, Brazil): phosphatebuffered saline; from LabSynth (Diadema, São Paulo, Brazil): ethanol, trisodium citrate, sodium carbonate, copper sulfate,

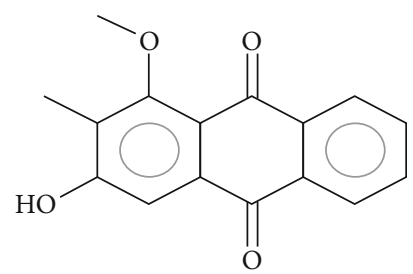

FIgURE 1: Chemical structure of the studied compound Rubiadin-1methyl ether.

double tartrate $\mathrm{Na} / \mathrm{K}$, and sodium hydroxide; from Newprov (Pinhais, Paraná, Brazil): Panoptic ${ }^{\circledR}$ dye; from Peprotech (Rocky Hill, New Jersey, USA): mouse TNF- $\alpha$ and IL-6 ELISA kits; from Rio de Janeiro Cell Bank (Rio de Janeiro, Rio de Janeiro, Brazil): RAW 264.7 macrophages; from Sigma-Aldrich Co. (St. Louis, Missouri, USA): lipopolysaccharide 0111:B4 (E. coli), Dexamethasone (minimum 98\% HPLC), Paclitaxel (minimum 95\% HPLC), 3(4,5-dimethylthiazol-2-yl)-2,5-diphenyltetrazolium bromide (MTT), hydrogen peroxide, hexadecyltrimethyl ammonium bromide, o-dianisidine $\% 2 \mathrm{HCl}\left(3,3^{\prime}\right.$ dimethoxybenzidine), $\alpha$-naphthylethylenediamide $\% 2 \mathrm{HCl}$, phenol, sodium azide, sodium dodecyl sulfate, sodium hypochlorite, sodium nitroprusside, sulfanilamide, and vanadium chloride (III); from Syntec (Hortolândia, São Paulo, Brazil): xylazine hydrochloride (2\%) and ketamine hydrochloride (10\%); from Vetec (Rio de Janeiro, Rio de Janeiro, Brazil): dimethyl sulfoxide, polysorbate-20 (5\%), sodium hydrogen phosphate, and zinc sulfate. The other reagents used and nonlisted were obtained from alternative commercial sources.

\subsection{In Vitro Experiments}

2.3.1. Cell Culture. RAW 264.7 murine macrophage cells were purchased from the Rio de Janeiro Cell Bank. The cells were maintained at $37^{\circ} \mathrm{C}$ in a $5 \% \mathrm{CO}_{2}$ humidified atmosphere and cultured in Dulbecco's modified Eagle medium (DMEM), supplemented with $10 \%$ fetal bovine serum (FBS) and $1 \%$ antibiotics $(100 \mathrm{U} / \mathrm{mL}$ penicillin, $100 \mu \mathrm{g} / \mathrm{mL}$ streptomycin). All experiments were conducted after verification of viable cells by the Trypan blue technique. The experiments were conducted between the 3th and 8th passages, and all in vitro assays were performed in triplicate and repeated on different days ( $n=3$ /group).

2.3.2. Cell Viability (Cytotoxicity). The compound cytotoxicity effect was evaluated by the MTT assay, already described [10]. The viability was measured after treatment with Rubiadin-1-methyl ether. For this, RAW 264.7 cells $\left(5 \times 10^{4}\right.$ cells/well) were seeded in 96-well plates and incubated at $37^{\circ} \mathrm{C}$ for $24 \mathrm{~h}$ until complete adherence and confluence (in a $5 \% \mathrm{CO}_{2}$ humidified atmosphere). The compound was tested at doses of 1 to $300 \mu \mathrm{M}$, diluted in $1 \%$ DMSO, and incubated for more $24 \mathrm{~h}$. Then the culture medium was replaced by MTT solution $(5 \mathrm{mg} / \mathrm{mL})$, followed by an incubation time of $2 \mathrm{~h}$. A control group was performed in these identical conditions, using the same amount of DMSO, and cell viability was considered $100 \%$. The MTT solution was removed, and 
the crystals were resuspended in DMSO. The results were evaluated by an ELISA reader, using a $450 \mathrm{~nm}$ wavelength.

Based on this test, it was possible to determine the $\mathrm{CC}_{10}$ of Rubiadin-1-methyl ether. The $\mathrm{CC}_{10}$ concentration represents the minimum necessary dose able to kill $10 \%$ of the cell line used [11] and was calculated through nonlinear regression analysis of the logarithm of concentration as a function of the normalized response (percentage of cell viability), using the software Prism 7.0 (GraphPad Software, La Jolla, CA, USA).

2.3.3. Cell Inflammation Assay. To establish an inflammatory condition, RAW 264.7 macrophages were stimulated with $E$. coli lipopolysaccharide (LPS $1 \mu \mathrm{g} / \mathrm{mL}$ ). For this procedure, cells were seeded in 96-well plates and incubated until complete full adherence and confluence $\left(37^{\circ} \mathrm{C}\right.$ for $24 \mathrm{~h}$; in a $5 \%$ $\mathrm{CO}_{2}$ humidified atmosphere). Next, cells were pretreated $(0.5 \mathrm{~h})$ according to the division groups, with subsequent induction by LPS $(1 \mu \mathrm{g} / \mathrm{mL})$. After $24 \mathrm{~h}$, the supernatants were collected and used to measure nitrite/nitrate (NOx) metabolite production and proinflammatory cytokine secretion (IL-6, IL- $1 \beta$, and TNF- $\alpha$ ).

The cell division groups were as follows: Blank control (B), represented by noninflamed cells that were only pretreated with vehicle (DMSO 1\%); negative control (LPS), characterized by inflamed LPS cells and pretreated with vehicle; positive control (Dexa), with cells pretreated with Dexamethasone $(7 \mu \mathrm{M})$ - a reference anti-inflammatory drug; and the treatment groups (Rub), represented by macrophages pretreated with the $\mathrm{CC}_{10}$ of Rubiadin-1-methyl ether ( $n=3$ /group).

2.3.4. Measurement of Nitric Oxide Metabolites. NO production was measured indirectly using the supernatant to quantify the formation of its metabolites nitrate $\left(\mathrm{NO}_{3}{ }^{-}\right)$and nitrite $\left(\mathrm{NO}_{2}{ }^{-}\right)$, through the Griess reaction [12]. The supernatant was collected $24 \mathrm{~h}$ after stimulation by LPS $(1 \mu \mathrm{g} / \mathrm{mL})$, and the aliquots were mixed with an equal volume of Griess reagent. After incubation for $10 \mathrm{~min}$, at room temperature, the results were determined by an ELISA plate reader at $540 \mathrm{~nm}$. The absorbance was measured by interpolation from the nitrite standard curve $(0-100 \mu \mathrm{M})$, and the results were expressed in $\mu \mathrm{M}$.

2.3.5. Quantification of Proinflammatory Cytokines (IL-6, IL$1 \beta$, and TNF- $\alpha$ ). The cytokines interleukin 6 (IL-6), interleukin 1 beta (IL-1 $\beta$ ) and tumor necrosis factor alpha (TNF- $\alpha$ ) present in the culture medium (supernatant) were measured by commercial kits, using the enzyme-linked immunosorbent assay (ELISA), following the manufacturer's instructions. Kits for IL- 6 and TNF- $\alpha$ were purchased from Peprotech (Rocky Hill, United States of America), while the kit used for IL-1 $\beta$ was purchased from BD Biosciences (San Diego, California, USA). The levels of cytokines were estimated by interpolation from a standard curve by colorimetric measurements at $450 \mathrm{~nm}$ in an ELISA plate reader. The results were expressed in $\mathrm{pg} / \mathrm{mL}$.

2.3.6. Determination of Macrophage Apoptosis. For this experiment, macrophages were seeded in 24-well plates and pretreated according to the division groups, with subsequent induction with LPS $(1 \mu \mathrm{g} / \mathrm{mL})$ followed by incubation of $0.5 \mathrm{~h}$. After $24 \mathrm{~h}$, cells were scraped with Versene ${ }^{\circledR}(0.2 \mathrm{~g}$ EDTA, $\mathrm{Na}_{4}$ ) and centrifuged with DMEM $(900 \mathrm{x} \mathrm{g}, 5 \mathrm{~min}$ at $4^{\circ} \mathrm{C}$ ). The groups were divided into the following: Blank control (B), represented by noninflamed cells only pretreated with vehicle (DMSO 1\%); negative control (LPS) characterized by inflamed LPS cells pretreated with vehicle; positive control (Pacli) cells pretreated with Paclitaxel $(30 \mu \mathrm{M})-\mathrm{a}$ reference proapoptotic drug; and the treatment groups (Dexa) pretreated with Dexamethasone $(7 \mu \mathrm{M})$ and (Rubiadin-1-methyl ether) pretreated with Rubiadin-1-methyl ether $(10,30$, and $100 \mu \mathrm{M})(n=3$ /group). In the next step, cells were washed with cold phosphate-buffered saline (PBS; pH 7.6) and centrifuged twice $\left(900 \mathrm{x} \mathrm{g}, 5 \mathrm{~min}\right.$ at $\left.4^{\circ} \mathrm{C}\right)$. The supernatant was discarded, and the pellets were suspended in binding buffer (0.1 M Hepes/ $\mathrm{NaOH}$ ( $\mathrm{pH} 7.4$ ), $1.4 \mathrm{M} \mathrm{NaCl}, 25 \mathrm{mM} \mathrm{CaCl}$ ). Next, the cells were stained with annexin $\mathrm{V}$ conjugated with fluorescein isothiocyanate (FITC) (BD Biosciences, San Jose, CA, USA) to analyze the apoptosis, following the manufacturer's instructions. The macrophages were differentiated from cell debris based on forward-scattered light (FSC) vs. side-scattered light (SSC) characteristics. The levels of apoptosis and necrosis on the macrophages were analyzed by a FACSVerse ${ }^{\circledR}$ flow cytometer (BD Biosciences, San Jose, CA, USA) using the FACSuite ${ }^{\circledR}$ software, in which 10,000 events were obtained. The results were expressed as percentages.

\subsection{In Vivo Experiments}

2.4.1. Animals. The study was conducted in 4 -week-old male Swiss mice weighing $20-25 \mathrm{~g}$. The animals were supplied by the Animal Centre from UFSC and were housed at constant room temperature $\left(20 \pm 2^{\circ} \mathrm{C}\right)$, under $12 \mathrm{~h}$ light/dark cycles, fed with standard mouse chow and water. After the induction with LPS, the mice were euthanized with an overdose of xylazine $/ \mathrm{ketamine}(30 \mathrm{mg} / \mathrm{kg}$ and $300 \mathrm{mg} / \mathrm{kg}$, respectively) and the samples were collected for further evaluations. The project was approved by the Committee for Ethics in Animal Research of UFSC (Protocol 6118110417).

2.4.2. LPS-Induced Acute Lung Injury (ALI) Model. The mice were randomly divided into 4 groups $(n=6$ /group): (S) Blank control (saline), represented by healthy animals and pretreated only with $0.9 \%$ sterile saline and vehicles (5\% Tween 20 and 5\% DMSO); (LPS) negative control, also pretreated with the vehicle and induced by LPS $(5 \mathrm{mg} / \mathrm{kg})$; (Dexa) positive control, pretreated with Dexamethasone (5 mg/kg, standard treatment animal); and Rubiadin-1methyl ether treated with Rubiadin-1-methyl ether $(3,10$, and $30 \mathrm{mg} / \mathrm{kg}$ ). All the pretreatments were conducted orally (gavage), and after $1 \mathrm{~h}$, all groups (except the Blank control) were anesthetized with xylazine/ketamine $(5 \mathrm{mg} / \mathrm{kg}$ and $50 \mathrm{mg} / \mathrm{kg}$ ) for intranasal LPS instillation $(5 \mathrm{mg} / \mathrm{kg}$ in $50 \mu \mathrm{L}$ PBS). After 12 hours, mice were euthanized by an overdose of xylazine/ketamine and bronchoalveolar lavage fluid (BALF) was collected [13]. Immediately after the BALF collection, the total and differential leukocyte counts and 
exudate concentration (protein content) were performed. Aliquots of BALF were stored in cryotubes and deposited in a freezer at $-80^{\circ} \mathrm{C}$ for further evaluations of myeloperoxidase (MPO) activity, NOx, and pro- and antiinflammatory cytokine (IL-6, IL-12p70, IL-10, IFN- $\gamma$, TNF- $\alpha$, and MCP-1) levels.

\subsubsection{Total Differential Leukocyte Count and Exudation on}

$B A L F$. The total leukocyte count in BALF was performed with Türk's solution (1:4). A common optical microscope (400x magnification) was used to quantify the cells in a Neubauer chamber. Cytospin slides of BALF were stained with Panoptic ${ }^{\circledR}$ dye for the differential count, which was performed under an oil immersion objective on a common optical microscope. The total and differential leukocyte counts were expressed as cells $\times 10^{5} / \mathrm{mL}$. The degree of capillarity leakage (exudation) was determined using the Lowry method [14], which quantifies the presence of total proteins in the samples. Bovine serum albumin was used as the standard, and exudation levels were expressed as $\mu \mathrm{g} / \mathrm{mL}$.

2.4.4. Determination of Myeloperoxidase (MPO) Activity in $B A L F$. The MPO assay was conducted according to methods previously described in the literature [15]. Briefly, BALF aliquots were mixed with HTAB (hexadecyltrimethyl ammonium bromide $0.5 \%$ ), subjected to three vortex/freeze-thaw cycles and centrifuged in refrigerated conditions $(40.000 \mathrm{x}$ g, $15 \mathrm{~min}$ at $4^{\circ} \mathrm{C}$ ). The supernatants were transferred to a 96-well plate, and MPO activity was performed by colorimetric measurements in an ELISA plate reader at $450 \mathrm{~nm}$ by interpolation from MPO (extracted from human leukocyte, Sigma-Aldrich Co.) standard curve $(0.07-140 \mathrm{mU} / \mathrm{mL})$. The results were expressed in $\mathrm{mU} / \mathrm{mL}$.

2.4.5. Determination of Nitric Oxide Levels (NOX) in BALF. The quantification of nitric oxide (NO) present in each sample was measured indirectly by the presence of its metabolic nitrate $\left(\mathrm{NO}_{3}^{-}\right)$and nitrite $\left(\mathrm{NO}_{2}^{-}\right)$, following the Griess reaction [16]. BALF aliquots were deproteinized using zinc sulfate (ZnSO4, 20\%), with subsequent overnight incubation at $-20^{\circ} \mathrm{C}$ in a freezer, with subsequent addition of sodium hydroxide $(\mathrm{NaOH}, 2.5 \mathrm{~N})$. The supernatants were transferred to 96-well plates and mixed with saturated vanadium chloride (VCI3) and Griess reagents. The colorimetric measurement was determined at $540 \mathrm{~nm}$ using an ELISA plate reader, and the amount of nitric oxide was determined indirectly by interpolation from the nitrite standard curve $(0-100 \mu \mathrm{M})$. The results were expressed in $\mu \mathrm{M}$.

2.4.6. Determination of Cytokine Levels in BALF. The proand anti-inflammatory cytokine (IL-6, IL-12p70, IL-10, IFN- $\gamma$, TNF- $\alpha$, and MCP-1) levels present in the BALF were determined by flow cytometry (BD Bioscience FACSVerse ${ }^{\circledR}$ Flow Cytometer), using a commercial kit (Cytometric Bead Array, CBA Mouse inflammation kit). The values were quantified using the FCAP Array ${ }^{\circledR}$ software. The detection limits for IL-6, IL-10, IL-12p70, MCP-1, INF- $\gamma$, and TNF- $\alpha$ were as follows: $5.00 \mathrm{pg} / \mathrm{mL}, 17.50 \mathrm{pg} / \mathrm{mL}$, $10.70 \mathrm{pg} / \mathrm{mL}, \quad 52.70 \mathrm{pg} / \mathrm{mL}, 2.50 \mathrm{pg} / \mathrm{mL}$, and $7.30 \mathrm{pg} / \mathrm{mL}$, respectively. The results were expressed in $\mathrm{pg} / \mathrm{mL}$.
2.4.7. Lung Histological Analysis. Mouse lungs were removed $12 \mathrm{~h}$ after LPS challenge, washed in PBS, and fixed in formalin solution $10 \%(v / v)$. The tissues were dehydrated in ethanol solutions, followed by xylene, then included in paraffin and sliced into $4 \mu \mathrm{m}$ sections (LEICA-Instruments ${ }^{\circledR}$ CM3050, Nussloch, Baden-Württemberg, Germany). Further, the slices were stained with hematoxylin-eosin and analyzed under light microscopy (200x). The lung damage was graded taking into account the degree of parenchymal distortion in the alveolar tissue. The scores used were as follows: 0 -normal, 1 -in-creased thickness in $<50 \%$ of interalveolar septa (IAS) due to edema and/or neutrophil infiltration, 2-increased thickness in $>50 \%$ of IAS, 3 -increased thickness in $>50 \%$ of IAS and the presence of neutrophils within the alveolar space, and 4-consolidated infiltration of neutrophils with distortion of normal alveolar architecture. The mean score was reported for each microscope section.

2.5. Statistical Analysis. The results were analyzed by GraphPad Prism ${ }^{\circledR}$ version 7.0 (San Diego, California, USA) and IBM SPSS Statistics 22. Parametric experimental results were expressed as mean \pm standard error of the mean (S.E.M.). Data residuals were analyzed for normality using the Shapiro-Wilk test and homoscedasticity using the Bartlett test. For the parametric homoscedastic data, one-way ANOVA followed by Tukey's post hoc test was used. Parametric heteroscedastic data were analyzed by one-way ANOVA-Welch followed by the Games-Howell post hoc test. Significance was set at $P<0.05$.

\section{Results}

\subsection{In Vitro Experiments}

3.1.1. Cytotoxicity of Rubiadin-1-methyl Ether. Rubiadin-1methyl ether did not exhibit significant toxicity, since this effect was observed only in high concentrations (up to $100 \mu \mathrm{M}$ ) (Figure 2(a)). Moreover, it was possible to determine the $\mathrm{CC}_{10}$ from this compound-a protocol used to ensure a $90 \%$ safe viability during the experiments (Figure 2(b)).

3.1.2. Effect of the Rubiadin-1-methyl Ether on NOx Levels. Next, NOx assay was performed using the $\mathrm{CC}_{10}$ value $(30 \mu \mathrm{M})$. In these experiments, Rubiadin-1-methyl ether was able to significantly inhibit NOx production (\% of inhibition: $44.7 \pm 9.6)(P<0.01)$ (Figure 3(a)). At the same manner, Dexamethasone also inhibited the synthesis of this inflammatory mediator (\% of inhibition: $58.1 \pm 4.9$ ) $(P<0.001)$ (Figure 3(a)).

3.1.3. Effect of the Rubiadin-1-methyl Ether on Proinflammatory Cytokines (IL-6, IL-1 $\beta$, and TNF- $\alpha$ ). In these experiments, Rubiadin-1-methyl ether at its $\mathrm{CC}_{10}$ dose significantly inhibited the production of IL- 6 and IL- $1 \beta$. The effect on IL-6 levels produced a significant inhibition (\% of inhibition: $52.1 \pm 3.2)(P<0.01)$ (Figure 3(b)). Likewise, Rubiadin-1-methyl ether significantly inhibited the IL-1 $\beta$ levels (\% of inhibition: $78.0 \pm 4.1)(P<0.001)$ (Figure 3(c)). On the other hand, this compound was not able to inhibit 


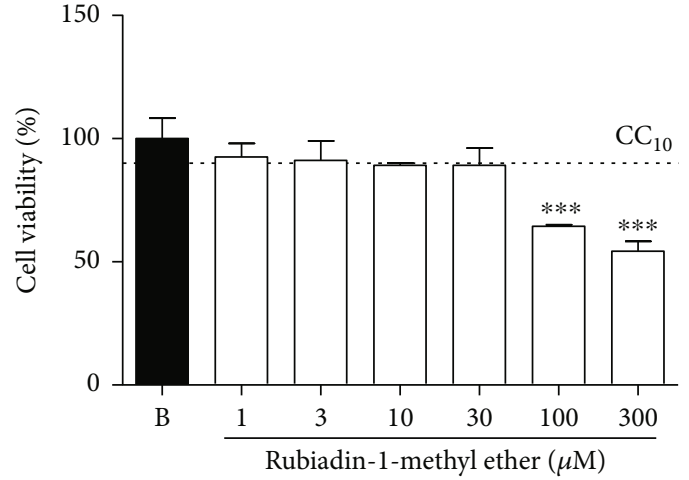

(a)

\begin{tabular}{lc}
\hline Compound & $\mathrm{CC}_{10}(\mu \mathrm{M})$ \\
\hline Rubiadin-1-methyl ether & 30 \\
\hline
\end{tabular}

(b)

FiguRE 2: Evaluation of Rubiadin-1-methyl ether cytotoxicity (RAW 264.7) (a) and calculated CC 10 (b) for this compound. B: cells pretreated with vehicle and stimulated with PBS; Rubiadin-1-methyl ether: cells pretreated with Rubiadin-1-methyl ether at doses at 1 to $300 \mu \mathrm{M}$. Each bar represents the average survival of the macrophages in independent experiments \pm S.D. $(n=3) .{ }^{* * *} P<0.001$.

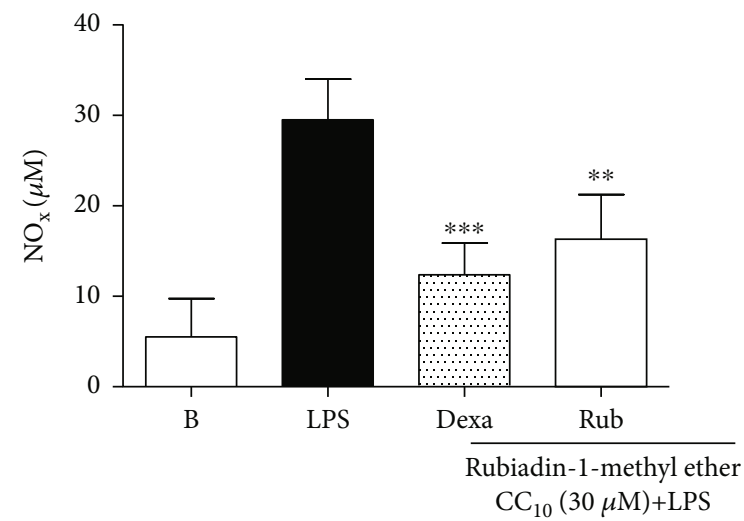

(a)

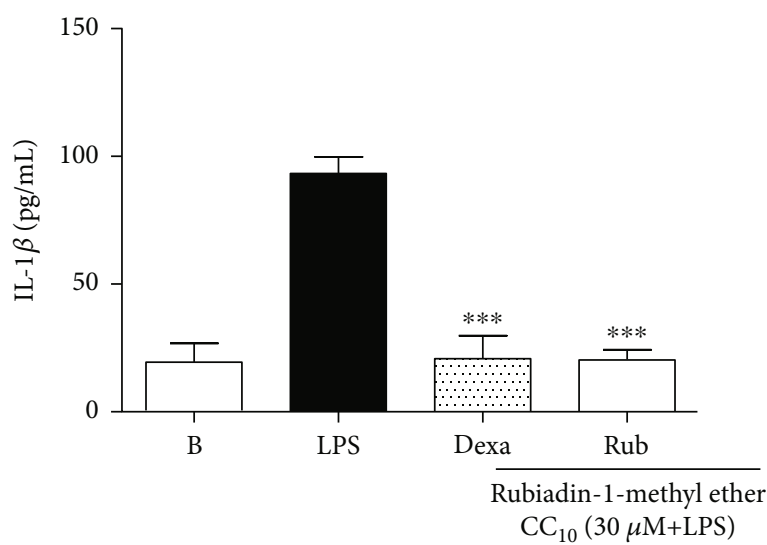

(c)

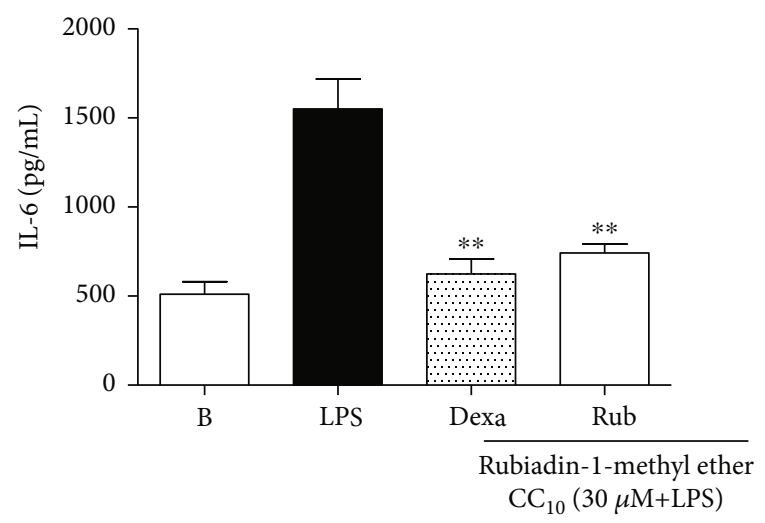

(b)

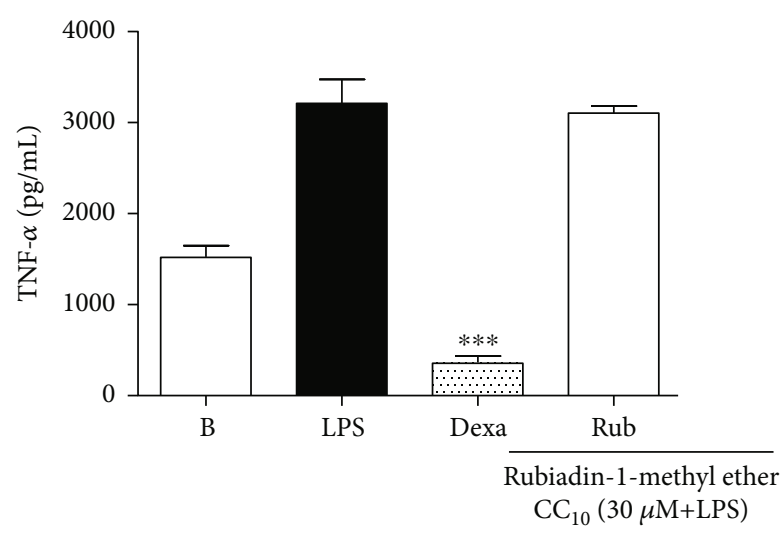

(d)

Figure 3: Effect of Rubiadin-1-methyl ether at $30 \mu \mathrm{M}$ dose on NOx (a), IL-6 (b), IL-1 $\beta$ (c), and TNF- $\alpha$ secretion (d) in RAW 264.7 macrophages stimulated with LPS. B: cells pretreated with vehicle and stimulated with PBS; LPS: cells stimulated with LPS ( $1 \mu \mathrm{g} / \mathrm{mL})$; Dexa: cells pretreated with Dexamethasone $(7 \mu \mathrm{M})$ and stimulated with LPS $(1 \mu \mathrm{g} / \mathrm{mL})$; Rub: cells pretreated with Rubiadin-1-methyl ether at $30 \mu \mathrm{M}$ and stimulated with LPS $(1 \mu \mathrm{g} / \mathrm{mL})$. The results were expressed as the mean \pm S.D.; $n=3 ;{ }^{* *} P<0.01$ and ${ }^{* * *} P<0.001$ compared with the LPS group.

the TNF- $\alpha$ levels $(P>0.05)$ (Figure 3(d)). As expected, Dexamethasone significantly reduced the levels of all cytokine studied (\% of inhibition: $59.7 \pm 5.4,77.4 \pm 9.3$, and $88.66 \pm$ 1.6) $(P<0.01)$ (Figures 3(b)-3(d)).
3.1.4. Effect of the Rubiadin-1-methyl Ether on Macrophage Apoptosis. Due to the significant correlation between the inflammatory process and the reduction on leukocyte apoptosis [17], we evaluated the possible action of Rubiadin-1- 


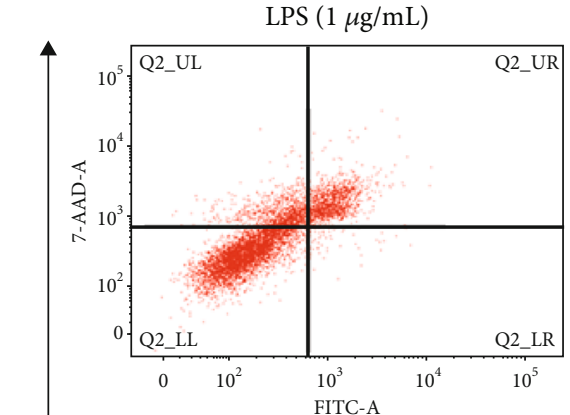

(a)

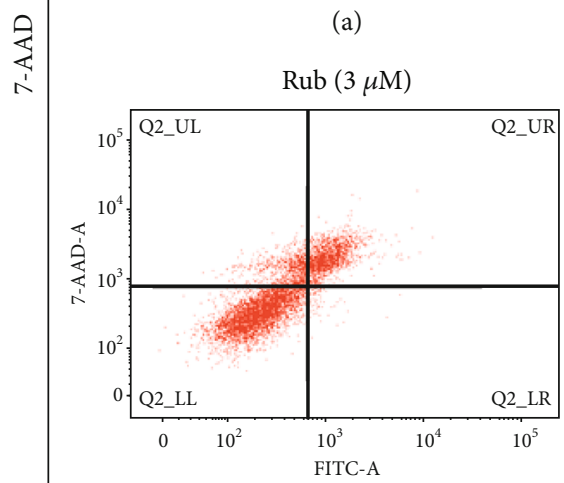

(d)

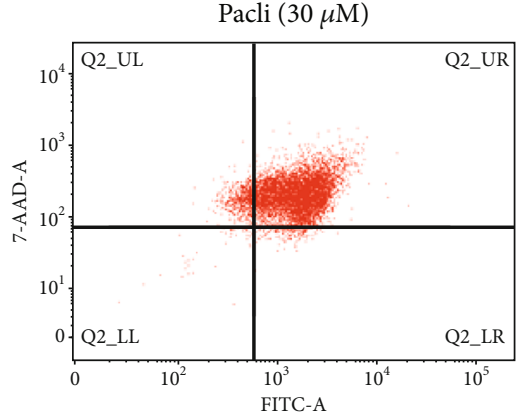

(b)

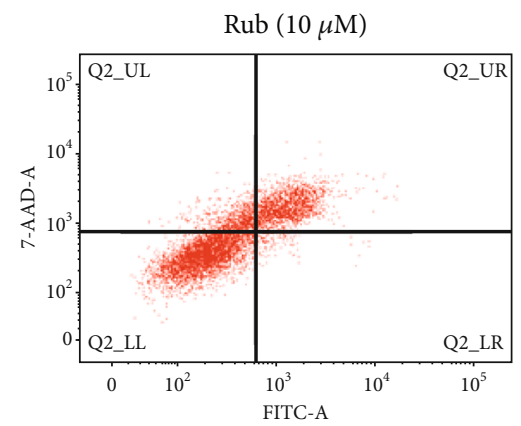

(e)

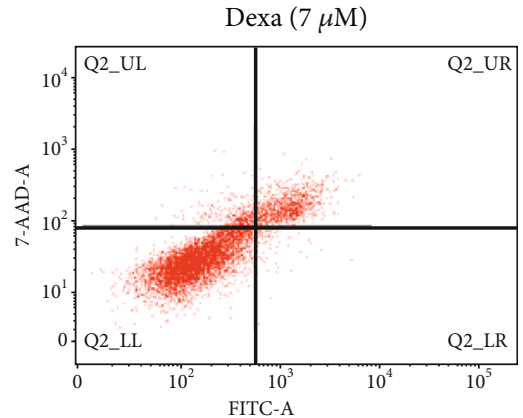

(c)

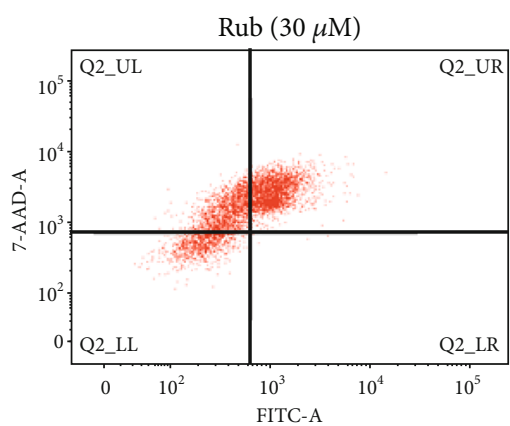

(f)

Annexin V-FITC

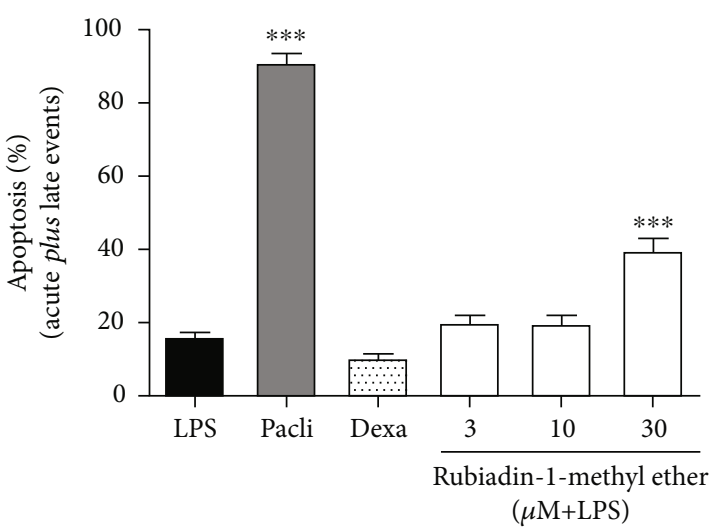

(g)

FIgURE 4: Flow cytometry dot plots representing the effect of Rubiadin-1-methyl ether on RAW 264.7 macrophage apoptosis (acute plus late events). LPS: cells stimulated with LPS $(1 \mu \mathrm{g} / \mathrm{mL})$ (a); Paclitaxel: cells pretreated with Paclitaxel at $30 \mu \mathrm{M}$ before LPS administration (b); Dexa: cells pretreated with Dexamethasone $(7 \mu \mathrm{M}) 30$ min before LPS administration (c); and Rub: cells pretreated with Rubiadin-1-methyl ether at $3 \mu \mathrm{M}$ (d), $10 \mu \mathrm{M}(\mathrm{e})$, and $30 \mu \mathrm{M}$ (f). Results presented at graphic mode (g) and expressed as the mean \pm S.D.; $n=3$; ${ }^{* * *} P<0.001$ compared with the LPS group.

methyl ether on this parameter. Our results demonstrated that Rubiadin-1-methyl ether was able to reverse the decrease in apoptosis rate produced by the inflammatory reaction when used at $30 \mu \mathrm{M}$ (\% of increase: $149.7 \pm 31.7$ ) $(P<0.001)$ (Figures $4(\mathrm{f})$ and $4(\mathrm{~g}))$. Dexamethasone also was not able to reverse this proinflammatory finding, when used at the tested concentration $(P>0.05)$ (Figures $4(\mathrm{c})$ and $4(\mathrm{~g})$ ).

\subsection{In Vivo Experiments}

3.2.1. Effect of the Rubiadin-1-methyl Ether on Cell Migration and Exudation. Rubiadin-1-methyl ether signifi- cantly decreased the total leukocyte count, showing a substantial inhibition when administrated at 10 and $30 \mathrm{mg} / \mathrm{kg}$ (\% of inhibition: $43.6 \pm 5.4$ and $55.3 \pm 5.8$ ), respectively $(P<0.001)$ (Figure 5(a)). This inhibition was due to the ability of this compound in reducing the neutrophil migration (\% of inhibition: $48.1 \pm 5.6$ and $68.8 \pm 4.7$ ), respectively $(P<0.001)$ (Figure 5(b)). Furthermore, Rubiadin-1methyl ether demonstrated the capacity to reduce exudate formation in the lungs. This decrease was observed in all tested doses $(3,10$, and $30 \mathrm{mg} / \mathrm{kg}$ ) (\% of inhibition: 55.5 $\pm 4.9,81.9 \pm 6.9$, and $82.9 \pm 45)$, respectively $(P<0.01)$ (Figure 5(c)). 


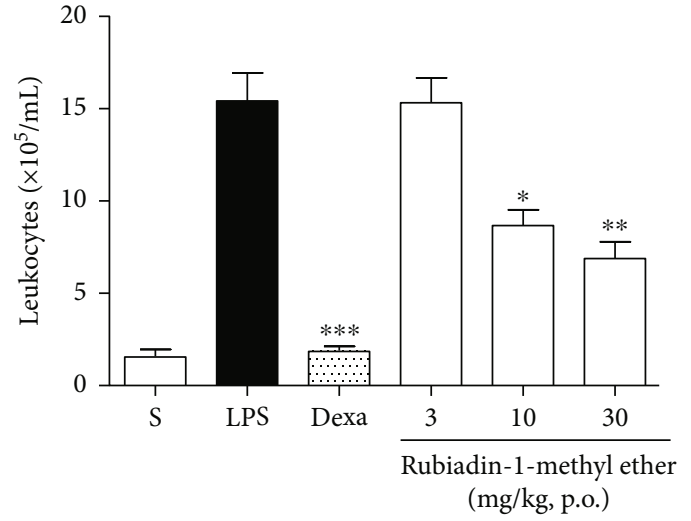

(a)

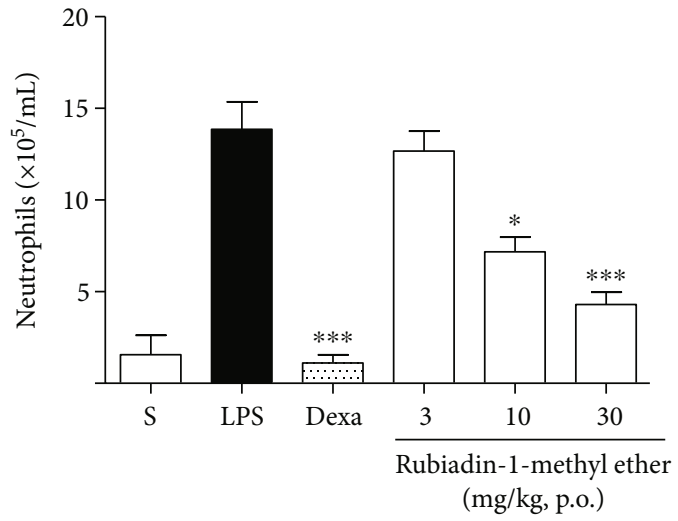

(b)

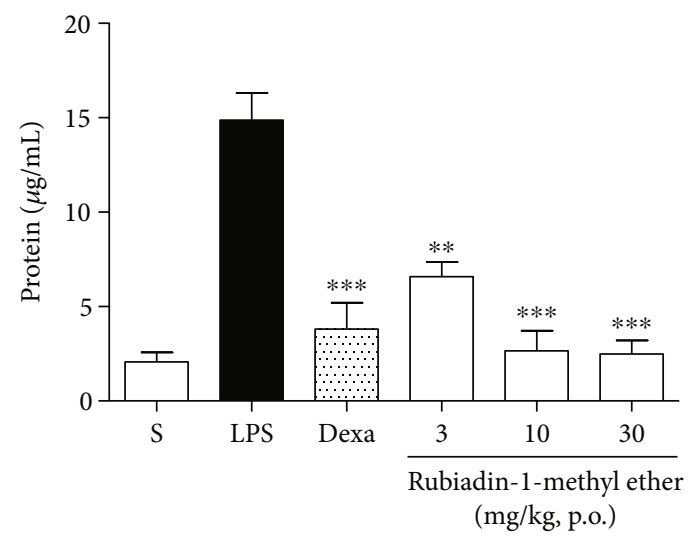

(c)

FIGURE 5: Effect of Rubiadin-1-methyl ether on total leukocyte counts (a), neutrophil counts (b), and exudation (c). S: healthy animals only treated with $0.9 \%$ sterile saline and vehicle ( $1 \%$ DMSO); LPS: (negative control) inflamed animals only stimulated with LPS ( $1 \mu \mathrm{g} / \mathrm{mL})$ at intranasal route (i.n.); Dexa: (positive control) animals pretreated with Dexamethasone (5 mg/kg, p.o.) $1 \mathrm{~h}$ before LPS administration; Rubiadin-1-methyl ether: animals pretreated with Rubiadin-1-methyl ether at doses of 3, 10, and $30 \mathrm{mg} / \mathrm{kg}$ (p.o.) $1 \mathrm{~h}$ before LPS administration. The results were expressed as the mean \pm S.D.; $n=6 ;{ }^{*} P<0.05,{ }^{* *} P<0.01$, and ${ }^{* * *} P<0.001$ compared with the LPS group.

\subsubsection{Effect of the Rubiadin-1-methyl Ether on Nitric Oxide} Levels (NOx) and Myeloperoxidase (MPO) Activity. Similar, to the in vitro experiments, Rubiadin-1-methyl ether also demonstrated effectiveness to reduce nitric oxide (NOx) metabolites, as well as MPO activity in the BALF. The NOx levels were reduced in all tested doses $(3,10$, and $30 \mathrm{mg} / \mathrm{kg})$ (\% of inhibition: $46.3 \pm 12.0,51.8 \pm 3.7$, and 60.1 \pm 8.7 ), respectively $(P<0.05)$ (Figure $6(\mathrm{a}))$. With the same pattern, this compound reduced the MPO activity in all tested doses (\% of inhibition: $41.8 \pm 4.5,50.1 \pm 2.5$, and $54.7 \pm 3.5$ ), respectively $(P<0.01)$ (Figure $6(\mathrm{~b}))$.

3.2.3. Effect of the Rubiadin-1-methyl Ether on Pro- and Anti-Inflammatory Cytokines. Rubiadin-1-methyl ether demonstrated a significant capacity on the decrease of the levels of all proinflammatory cytokines studied at least, in one of the tested doses. IL-12p70 and IL- 6 demonstrated a significant inhibition in all tested doses (\% of inhibition: $3 \mathrm{mg} / \mathrm{kg}: 37.1 \pm 11.3,10 \mathrm{mg} / \mathrm{kg}: 47.4 \pm 13.9$, and $30 \mathrm{mg} / \mathrm{kg}$ : $79.5 \pm 8.2$ ) and (\% of inhibition: $3 \mathrm{mg} / \mathrm{kg}$ : $33.7 \pm 10.5$, $10 \mathrm{mg} / \mathrm{kg}: 49 \pm 6.9$, and $30 \mathrm{mg} / \mathrm{kg}: 79.5 \pm 6.8$ ), respectively $(P<0.05)$ (Table 1$)$. INF- $\gamma$ demonstrated a significant reduction when Rubiadin-1-methyl ether was used at 10 and
$30 \mathrm{mg} / \mathrm{kg} \quad(\%$ of inhibition: $10 \mathrm{mg} / \mathrm{kg}: \quad 64.5 \pm 5.6$ and $30 \mathrm{mg} / \mathrm{kg}: 88.4 \pm 1.8)(P<0.01)$ (Table 1$)$, while the chemokine MCP-1 showed a significant reduction only when the compound was used at the highest tested dose (\% of inhibition: $30 \mathrm{mg} / \mathrm{kg}: \quad 82.6 \pm 7.2) \quad(P<0.01) \quad$ (Table 1). In contrast with the results obtained in vitro, Rubiadin-1methyl ether was able to reduce TNF- $\alpha$ production, at a significant manner in an in vivo model (\% of inhibition: $10 \mathrm{mg} / \mathrm{kg}: 27.7 \pm 6.6$ and $30 \mathrm{mg} / \mathrm{kg}: 69.2 \pm 11.4)(P<0.05)$ (Table 1). Furthermore, this compound caused a significant increase in the production of IL-10 when administrated at 10 and $30 \mathrm{mg} / \mathrm{kg}$ (\% of increase: $10 \mathrm{mg} / \mathrm{kg}$ : $324.8 \pm 67$ and $30 \mathrm{mg} / \mathrm{kg}: 360.5 \pm 74.8)(P<0.001)$ (Table 1$)$.

3.2.4. Effect of the Rubiadin-1-methyl Ether on Lung Histological Architecture. The acute lung injury induction by LPS intranasal instillation provided a massive leukocyte infiltration with a consequent loss of lung architecture. The pretreatment with Rubiadin-1-methyl ether reduced this lung damage with a statistical significance, at the dose of $30 \mathrm{mg} / \mathrm{kg}$ (\% inhibition: $43.4 \pm 4.3$ ) (Figure 7). Dexamethasone treatment also significantly reduced the 


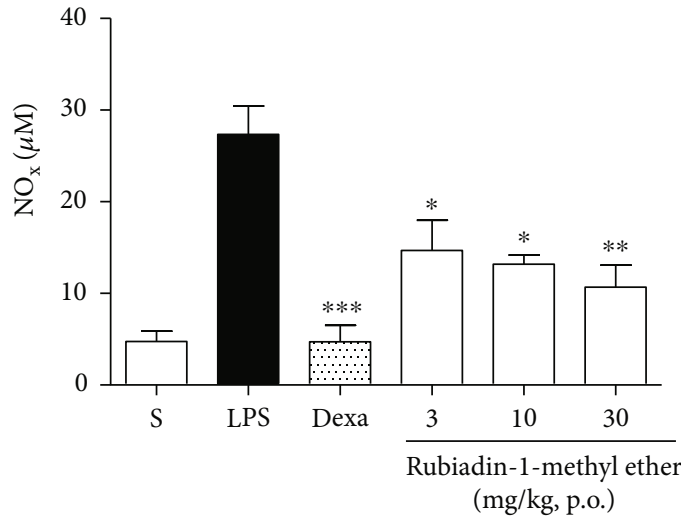

(a)

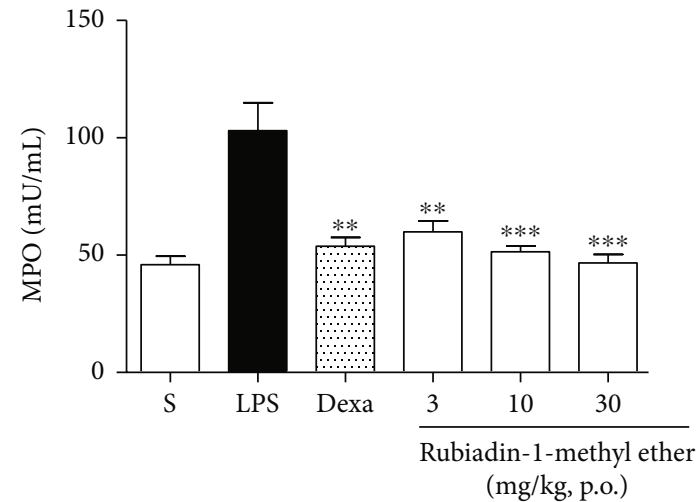

(b)

FIGURE 6: Measurement of NO levels and MPO activity. Effect of Rubiadin-1-methyl ether on measurement of NO levels (a) and MPO activity (b). S: healthy animals only treated with $0.9 \%$ sterile saline and vehicle ( $1 \% \mathrm{DMSO})$; LPS: (negative control) inflamed animals only stimulated with LPS $(1 \mu \mathrm{g} / \mathrm{mL}$ ) at intranasal route (i.n.).; Dexa: (positive control) animals pretreated with Dexamethasone (5 mg/kg, p.o.) $1 \mathrm{~h}$ before LPS administration; Rubiadin-1-methyl ether: animals pretreated with Rubiadin-1-methyl ether at doses at 3, 10, and 30 mg/kg (p.o.) $1 \mathrm{~h}$ before LPS administration. The results were expressed as the mean \pm S.D.; $n=6$; ${ }^{*} P<0.05,{ }^{* *} P<0.01$, and ${ }^{* * *} P<0.001$ compared with the LPS group.

TABLE 1: Effects of Rubiadin-1-methyl ether on pro- and anti-inflammatory cytokine levels in LPS-induced acute lung injury (ALI) in mice.

\begin{tabular}{lcccccc}
\hline Cytokines & TNF- $\alpha(\mathrm{pg} / \mathrm{mL})$ & IL-6 $(\mathrm{pg} / \mathrm{mL})$ & MCP-1 $(\mathrm{pg} / \mathrm{mL})$ & IL-12p70 $(\mathrm{pg} / \mathrm{mL})$ & INF- $\gamma(\mathrm{pg} / \mathrm{mL})$ & IL-10 $(\mathrm{pg} / \mathrm{mL})$ \\
\hline S & $136.0 \pm 17.3$ & $6.9 \pm 0.8$ & $21.9 \pm 7.1$ & $2.1 \pm 0.3$ & $2.8 \pm 0.9$ & $9.7 \pm 1.0$ \\
LPS & $7102.0 \pm 645.0$ & $4481 \pm 153.8$ & $609.0 \pm 44.5$ & $48.8 \pm 3.8$ & $399.8 \pm 80.8$ & $3.7 \pm 0.7$ \\
Dexa & $298.5 \pm 76.0^{* * *}$ & $270.0 \pm 27.0^{* * *}$ & $20.9 \pm 5.2^{* * *}$ & $4.8 \pm 1.2^{* * *}$ & $2.7 \pm 0.8^{* * *}$ & $9.0 \pm 1.9^{*}$ \\
Rub (3) & $6229.0 \pm 986.2$ & $2968.0 \pm 469.7^{*}$ & $507.3 \pm 158.5$ & $30.7 \pm 5.5^{*}$ & $259.3 \pm 56.3$ & $3.3 \pm 0.9$ \\
Rub (10) & $5162.0 \pm 471.6^{*}$ & $2285.0 \pm 311.9^{* * *}$ & $444.3 \pm 65.9$ & $25.7 \pm 6.8^{*}$ & $141.8 \pm 22.5^{* *}$ & $15.8 \pm 2.5^{* * *}$ \\
Rub (30) & $2188.0 \pm 812.4^{* * *}$ & $921.1 \pm 308.3^{* * *}$ & $105.9 \pm 43.9^{* *}$ & $10.0+4.0^{* * *}$ & $46.3 \pm 7.2^{* * *}$ & $17.1 \pm 2.8^{* * *}$ \\
\hline
\end{tabular}

S: health animals treated with vehicle per oral $0.5 \mathrm{~h}$ before intranasal instillation with sterile saline; LPS: negative control, also pretreated with vehicle and induced by LPS ( $5 \mathrm{mg} / \mathrm{kg})$; Dexa: positive control, pretreated with Dexamethasone $(5 \mathrm{mg} / \mathrm{kg})$ per oral administrated $0.5 \mathrm{~h}$ before acute lung injury induction; Rub: treatment with Rubiadin-1-methyl ether $(3,10$, and $30 \mathrm{mg} / \mathrm{kg})$ administered per oral $0.5 \mathrm{~h}$ before LPS-induced acute lung injury. Each group represents the mean \pm SEM; $\mathrm{N}=5$ animals; ${ }^{*} P<0.05 ;{ }^{* *} P<0.01 ;{ }^{* * *} P<0.001$.

histological parameters studied (\% inhibition: $47.7 \pm 6.7$ ) $(P<0.001)$ (Figure 7).

\section{Discussion}

Despite intense efforts to use approved drugs in the treatment of critical medical conditions like ALI, nowadays, there is no medicine that can significantly improve the poor prognosis of this condition $[18,19]$. However, the use of glucocorticoids as an adjuvant therapy to prevent the progression of ALI to circulatory and metabolic dysfunction is an approach used worldwide [20,21]. Studies have therefore focused on the search for a compound capable of reversing this clinical situation.

Natural products are the most versatile source of new compounds with biologicals effects, since the majority of drugs currently in use are derived or synthesized from natural molecules and their products [22]. Anthraquinones, a natural class of compounds used as laxative, antimalarial $[23,24]$, anticancer [25], and antiviral [26] treatments, recently demonstrated anti-inflammatory action by interfer- ing in the intracellular signaling related to the activation of STAT proteins [27]. It is not unexpected that signaling conducted by various STATs, particularly STAT3, will be closely interconnected with NF- $\kappa \mathrm{B}$ signaling-the nuclear factor responsible for managing the production of proinflammatory mediators in ALI, sepsis, and systemic shock [28-30].

Among the main mediators involved in the development of ALI and systemic shock initiated by LPS [31], NO deserves a highlighted role, as it is the main factor responsible for producing uncontrolled systemic vasodilatation, leading to intravascular coagulation and, in critical cases, culminating in organ failure $[32,33]$. NO production, in the inflammatory context, is mainly conducted by iNOS (inducible nitric oxide synthase) that produces 100 to $1000 x$ more NO than the constitutive isoforms [34]. In our experiments, Rubiadin-1methyl ether, a major anthraquinone isolated from Pentas schimperi, showed significant capacity to inhibit the production of this mediator in both models-in vitro and in vivo. A similar effect was observed in the in vitro experiments conducted by Alves and coworkers, who demonstrated an inhibitory effect of mitoxantrone (an anthraquinone used in 

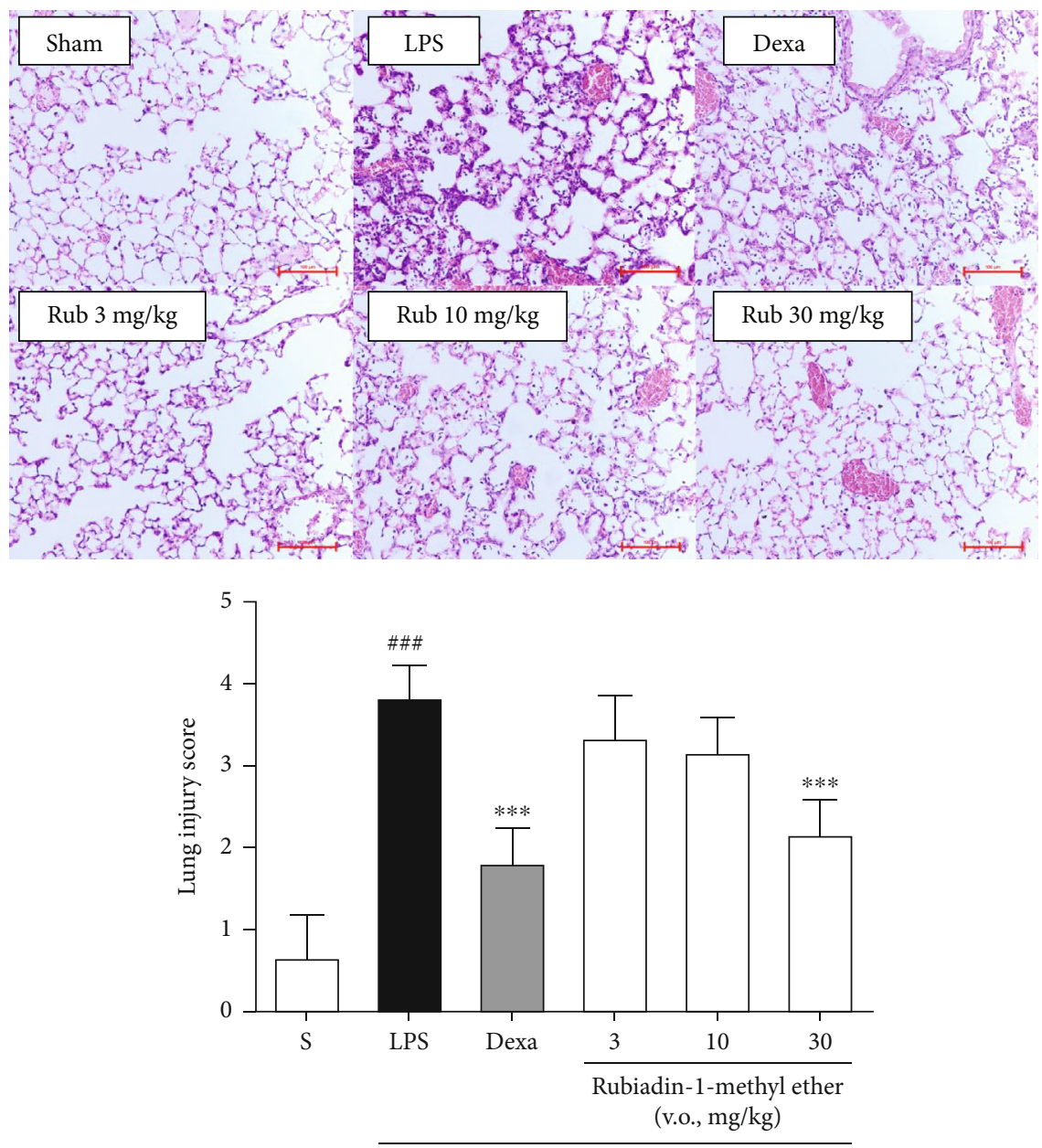

LPS, i.n., $5 \mathrm{mg} / \mathrm{kg}$

FiguRE 7: Effect of Rubiadin-1-methyl ether on lung architecture in LPS-induced acute lung injury mice. Sham: animals treated with vehicle per oral $1 \mathrm{~h}$ before intranasal instillation with sterile saline; LPS: (negative control) animals treated with vehicle per oral $1 \mathrm{~h}$ before intranasal instillation with sterile LPS; Dexa: (positive control) animals treated with dexamethasone per oral (5 mg/kg) $1 \mathrm{~h}$ before intranasal instillation with sterile LPS; Rub (3, 10, and $30 \mathrm{mg} / \mathrm{kg}$ ): animals treated with Rubiadin-1-methyl ether per oral (3, 10, and $30 \mathrm{mg} / \mathrm{kg}) 1 \mathrm{~h}$ before intranasal instillation with sterile LPS. Each group represents the mean \pm standard error of the mean; $n=6 /$ group. $\# \# \# P<0.001$ compared to the Sham group. ${ }^{* * *} P<0.001$ compared to the LPS group.

anticancer therapy) on NO levels, using a model of J774 macrophages stimulated by LPS [35]. More recently, Vien et al. showed, through their research, the inhibitory effects of seven different anthraquinones on NO levels. This effect was attributed to the ability of these compounds to inhibit iNOS expression in the same in vitro inflammatory model as that used in our experiments [36].

Besides regulating nitric oxide production, reducing the progression to ALI from systemic shock, chemokines and pro- and anti-inflammatory cytokines like TNF- $\alpha$, IL- 6 , IL12 , IFN- $\gamma$, MCP-1, and IL-10 are important mediators involved in the establishment of ALI critical findings [37, 38]. The excessive production of proinflammatory cytokines and chemokines promotes the expression of tissue growth factors produced by activated macrophages and leads to a coagulation disorder culminating in multiple organ failure [39]. In this context, our results demonstrated that Rubiadin-1-methyl ether tested in vitro, as well as in vivo, was able to reduce the production of proinflammatory cyto- kines and chemokines induced by LPS. Moreover, this compound was able to increase the production of IL-10, a cytokine with anti-inflammatory profile. Corroborating with our results, other authors have also observed the same inhibitory effects related to different anthraquinone compounds. Likewise, the experiments conducted by $\mathrm{Hu}$ and coworkers demonstrated an inhibitory action of aloe emodin from rhubarb on NOx levels, as well on proinflammatory cytokines (IL-6 and IL-1 $\beta$ ) [40]. Another study, conducted by Wu et al., demonstrated a significant reduction on the production of proinflammatory cytokines when U937 and RAW 264.7 cells were pretreated with 6-hydroxyrubiadin before stimulation with phorbol myristate acetate (PMA) and LPS, respectively [41]. These authors also proved that 6hydroxyrubiadin had important in vivo effects, demonstrating that this anthraquinone maintains an inhibitory effect on proinflammatory cytokines in mice pretreated before LPS administration, significantly attenuating the severity of LPS-induced ALI [41]. 
In addition, the ability of Rubiadin-1-methyl ether to increase the secretion of IL-10 deserves to be highlighted, since this effect can be considered a highly desirable regulatory mechanism in inflammatory conditions. Recently, IL-10 has been shown to be an important cytokine responsible for shifting the macrophage function, promoting the modulation of cellular metabolism, and resulting in the immunomodulation of the inflammatory reaction [42]. This cytokine is emphasized in the inflammatory process due its regulatory character, balancing and suppressing the expression of proinflammatory cytokines, such as IL6 , IL-1 $\beta$, and TNF- $\alpha$ [43]. Similar results were obtained by Meng et al. who demonstrated that Rheum tanguticum Maxim. ex Balf. (Rt), a traditional Tibetan medicine rich in anthraquinones, had anti-inflammatory effects by inhibiting the secretion of proinflammatory cytokines and NO. Furthermore, an immunomodulatory character was revealed based on the ability of this compound to stimulate the secretion of IL-10 on primary microglia cells from the cerebral cortex of C57BL/6 mice [44].

In conjunction with the reduction in plasma extravasation, the reduction in neutrophil recruitment is one of the steps necessary to reconstitute tissue homeostasis on ALI, followed by a return to the normal rate of inflammatory cell apoptosis $[45,46]$. In this sense, our in vivo experiments demonstrated that Rubiadin-1-methyl ether had the ability to reduce fluid leakage and leukocyte influx in the BALF. This effect can be attributed to its capacity in reduce neutrophil migration and activation (MPO). Moreover, our in vitro assays demonstrated that macrophages reestablished the normal apoptosis rate when pretreated with Rubiadin-1-methyl ether before LPS administration. Other researchers have already attributed this effect to anthraquinone compounds, e.g., Wang and coworkers, who demonstrated, using an elegant experimental model, that emodin was able to reestablish the apoptosis rate on neutrophils isolated from rats with severe acute pancreatitis induced by sodium taurocholate [47]. In fact, contact with apoptotic neutrophils may shift the profile of proinflammationactivated macrophages to an anti-inflammatory state [48], as the interplay between apoptotic cells and mononuclear phagocytes suppresses the inflammatory responses and facilitates apoptotic cell clearance [49]. Taken together, the findings obtained in our experiments allowed us to hypothesize that the compound studied probably reduces the need for the macrophages to sustain a proinflammatory phenotype (M1), at least in the LPS models used.

\section{Conclusion}

In summary, we demonstrated that the compound Rubiadin1-methyl ether has significant anti-inflammatory activity, showing an immunomodulatory profile. This compound may therefore be a potential candidate for the development of treatments for inflammatory conditions in which LPS is closely related, such as acute lung injury (ALI). However, further studies are needed to accurately elucidate the exact mechanism of action in the LPS cell pathway.

\section{Data Availability}

No data were used to support this study.

\section{Conflicts of Interest}

The authors declare no conflict of interest.

\section{Acknowledgments}

This work was supported by the Conselho Nacional de Desenvolvimento Científico e Tecnológico (CNPq, Brazil) and Coordenação de Aperfeiçoamento de Pessoal de Nível Superior (CAPES, Brazil).

\section{References}

[1] E. M. Malik and C. E. Müller, "Anthraquinones as pharmacological tools and drugs," Medicinal Research Reviews, vol. 36, no. 4, pp. 705-748, 2016.

[2] J. M. Watt and M. G. Breyer-Brandwijk, The Medicinal and Poisonous Plants of Southern and Eastern Africa: Being an Account of their Medicinal and Other Uses, Chemical Composition, Pharmacological Effects and Toxicology in Man and Animal, Edinburgh, E. \& S. Livingstone, 2 edition, 1962.

[3] J. Marioni, M. A. da Silva, J. L. Cabrera, S. C. Montoya, and M. G. Paraje, "The anthraquinones rubiadin and its 1-methyl ether isolated from Heterophyllaea pustulata reduces Candida tropicalis biofilms formation," Phytomedicine, vol. 23, no. 12, pp. 1321-1328, 2016.

[4] M. Endale, J. P. Alao, H. M. Akala et al., "Antiplasmodial quinones from Pentas longiflora and Pentas lanceolata," Planta Medica, vol. 78, no. 1, pp. 31-35, 2012.

[5] M. Endale, A. Ekberg, J. P. Alao et al., "Anthraquinones of the roots of Pentas micrantha," Molecules, vol. 18, no. 1, pp. 311$321,2013$.

[6] M. E. Kotas and R. Medzhitov, "Homeostasis, inflammation, and disease susceptibility," Cell, vol. 160 , no. 5, pp. 816-827, 2015.

[7] K. Hamidzadeh, S. M. Christensen, E. Dalby, P. Chandrasekaran, and D. M. Mosser, "Macrophages and the recovery from acute and chronic inflammation," Annual Review of Physiology, vol. 79, pp. 567-592, 2017.

[8] M. Dadar, Y. Shahali, S. Chakraborty et al., "Antiinflammatory peptides: current knowledge and promising prospects," Inflammation Research, vol. 68, no. 2, pp. 125-145, 2019.

[9] V. Kuete, A. R. N. Donfack, A. T. Mbaveng, M. Zeino, P. Tane, and T. Efferth, "Cytotoxicity of anthraquinones from the roots of Pentas schimperi towards multi-factorial drug-resistant cancer cells," Investigational New Drugs, vol. 33, no. 4, pp. 861-869, 2015.

[10] T. Mosmann, "Rapid colorimetric assay for cellular growth and survival: application to proliferation and cytotoxicity assays," Journal of Immunological Methods, vol. 65, no. 1-2, pp. 55-63, 1983.

[11] C. Chan, P. Martin, N. J. Liptrott, M. Siccardi, L. Almond, and A. Owen, "Incompatibility of chemical protein synthesis inhibitors with accurate measurement of extended protein degradation rates," Pharmacology Research \& Perspectives, vol. 5, no. 5, pp. 1-12, 2017. 
[12] L. C. Green, D. A. Wagner, J. Glogowski, P. L. Skipper, J. S. Wishnok, and S. R. Tannenbaum, "Analysis of nitrate, nitrite, and $\left[{ }^{15} \mathrm{~N}\right]$ nitrate in biological fluids," Analytical Biochemistry, vol. 126, no. 1, pp. 131-138, 1982.

[13] M. V. P. dos Santos Nascimento, A. C. M. Munhoz, B. M. De Campos Facchin et al., "New pre-clinical evidence of antiinflammatory effect and safety of a substituted fluorophenyl imidazole," Biomedicine \& Pharmacotherapy, vol. 111, pp. 1399-1407, 2019.

[14] O. H. Lowry, N. J. Rosebrough, A. L. Farr, and R. J. Randall, "Protein measurement with the folin phenol reagent," Journal of Biological Chemistry, vol. 193, no. 1, pp. 265-275, 1951.

[15] P. P. Bradley, D. A. Priebat, R. D. Christensen, and G. Rothstein, "Measurement of cutaneous inflammation: estimation of neutrophil content with an enzyme marker," The Journal of Investigative Dermatology, vol. 78, no. 3, pp. 206209, 1982.

[16] K. M. Miranda, M. G. Espey, and D. A. Wink, “A rapid, simple spectrophotometric method for simultaneous detection of nitrate and nitrite," Nitric Oxide: Biology and Chemistry, vol. 5, no. 1, pp. 62-71, 2001.

[17] M. A. Sugimoto, J. P. Vago, M. Perretti, and M. M. Teixeira, "Mediators of the resolution of the inflammatory response," Trends in Immunology, vol. 40, no. 3, pp. 212-227, 2019.

[18] M. P. Fink and H. S. Warren, "Strategies to improve drug development for sepsis," Nature Reviews - Drug Discovery, vol. 13, no. 10, pp. 741-758, 2014.

[19] M. Cecconi, L. Evans, M. Levy, and A. Rhodes, "Sepsis and septic shock," The Lancet, vol. 392, no. 10141, pp. 75-87, 2018.

[20] B. Venkatesh, S. Finfer, J. Cohen et al., "Adjunctive glucocorticoid therapy in patients with septic shock," The New England Journal of Medicine, vol. 378, no. 9, pp. 797-808, 2018.

[21] S. L. Rygård, E. Butler, A. Granholm et al., "Low-dose corticosteroids for adult patients with septic shock: a systematic review with meta-analysis and trial sequential analysis," Intensive Care Medicine, vol. 44, no. 7, pp. 1003-1016, 2018.

[22] D. J. Newman and G. M. Cragg, "Natural products as sources of new drugs from 1981 to 2014," Journal of Natural Products, vol. 79, no. 3, pp. 629-661, 2016.

[23] C. P. Osman, N. H. Ismail, R. Ahmad, N. Ahmat, K. Awang, and F. M. Jaafar, "Anthraquinones with antiplasmodial activity from the roots of Rennellia elliptica Korth. (Rubiaceae)," Molecules, vol. 15, no. 10, pp. 7218-7226, 2010.

[24] B. C. Lin, D. R. Harris, L. M. D. Kirkman et al., "The anthraquinone emodin inhibits the non-exported FIKK kinase from Plasmodium falciparum," Bioorganic Chemistry, vol. 75, pp. 217-223, 2017.

[25] A. S. Tikhomirov, A. A. Shtil, and A. E. Shchekotikhin, "Advances in the discovery of anthraquinone-based anticancer agents," Recent Patents on Anti-Cancer Drug Discovery, vol. 13, no. 2, pp. 159-183, 2018.

[26] Prateeksha, M. A. Yusuf, B. N. Singh et al., "Chrysophanol: a natural anthraquinone with multifaceted biotherapeutic potential," Biomolecules, vol. 9, no. 2, pp. 1-24, 2019.

[27] D. Bhasin, J. P. Etter, S. N. Chettiar, M. Mok, and P. K. Li, "Antiproliferative activities and SAR studies of substituted anthraquinones and 1,4-naphthoquinones," Bioorganic \& Medicinal Chemistry Letters, vol. 23, no. 24, pp. 6864-6867, 2013.
[28] H. Lee, A. Herrmann, J. Deng et al., "Persistently activated stat 3 maintains constitutive NF- $\kappa$ B activity in tumors," Cancer Cell, vol. 15, no. 4, pp. 283-293, 2009.

[29] T. Welte, S. S. M. Zhang, T. Wang et al., "STAT3 deletion during hematopoiesis causes Crohn's disease-like pathogenesis and lethality: a critical role of STAT3 in innate immunity," Proceedings of the National Academy of Sciences of the United States of America, vol. 100, no. 4, pp. 1879-1884, 2003.

[30] J. Yang, X. Liao, M. K. Agarwal, L. Barnes, P. E. Auron, and G. R. Stark, "Unphosphorylated STAT3 accumulates in response to IL-6 and activates transcription by binding to NFאB," Genes \& Development, vol. 21, no. 11, pp. $1396-$ 1408, 2007.

[31] F. Vannini, K. Kashfi, and N. Nath, "The dual role of iNOS in cancer," Redox Biology, vol. 6, pp. 334-343, 2015.

[32] C. Thiemermann, "Nitric oxide and septic shock," General Pharmacology, vol. 29, no. 2, pp. 159-166, 1997.

[33] M. S. Winkler, S. Kluge, M. Holzmann et al., "Markers of nitric oxide are associated with sepsis severity: an observational study," Critical Care, vol. 21, no. 1, pp. 189-197, 2017.

[34] M. Lind, A. Hayes, M. Caprnda et al., "Inducible nitric oxide synthase: good or bad?," Biomedicine \& Pharmacotherapy, vol. 93, pp. 370-375, 2017.

[35] C. C. S. Alves, C. F. Da Costa, S. B. R. De Castro et al., "Synthesis and evaluation of cytotoxicity and inhibitory effect on nitric oxide production by J774A.1 macrophages of new anthraquinone derivatives," Medicinal Chemistry, vol. 9, no. 6, pp. 812-818, 2013.

[36] L. T. Vien, T. T. H. Hanh, P. T. T. Huong et al., "Anthraquinone and butenolide constituents from the crinoid capillaster multiradiatus," Chemical and Pharmaceutical Bulletin, vol. 66, no. 11, pp. 1023-1026, 2018.

[37] M. Levi and T. van der Poll, "Coagulation and sepsis," Thrombosis Research, vol. 149, pp. 38-44, 2017.

[38] H. Matsumoto, H. Ogura, K. Shimizu et al., "The clinical importance of a cytokine network in the acute phase of sepsis," Scientific Reports, vol. 8, pp. 13995-14006, 2018.

[39] M. Levi and T. van der Poll, "Endothelial injury in sepsis," Intensive Care Medicine, vol. 39, no. 10, pp. 1839-1842, 2013.

[40] B. Hu, H. Zhang, X. Meng, F. Wang, and P. Wang, "Aloe-emodin from rhubarb (Rheum rhabarbarum) inhibits lipopolysaccharide- induced inflammatory responses in RAW264.7 macrophages," Journal of Ethnopharmacology, vol. 153, no. 3, pp. 846-853, 2014.

[41] Y. Wu, F. Jin, Y. Wang, F. Li, Z. Ren, and Y. Wang, "In vitro and in vivo inhibitory effects of 6-hydroxyrubiadin on lipopolysaccharide-induced inflammation," Immunopharmacology and Immunotoxicology, vol. 39, no. 3, pp. 107-116, 2017.

[42] W. K. E. Ip, N. Hoshi, D. S. Shouval, S. Snapper, and R. Medzhitov, "Anti-inflammatory effect of IL-10 mediated by metabolic reprogramming of macrophages," Science, vol. 356, no. 6337, pp. 513-519, 2017.

[43] W. Ouyang, S. Rutz, N. K. Crellin, P. A. Valdez, and S. G. Hymowitz, "Regulation and functions of the IL-10 family of cytokines in inflammation and disease," Annual Review of Immunology, vol. 29, pp. 71-109, 2011.

[44] J. Meng, J. Ni, Z. Wu et al., "The critical role of IL-10 in the antineuroinflammatory and antioxidative effects of Rheum tanguticum on activated microglia," Oxidative Medicine and 
Cellular Longevity, vol. 2018, Article ID 1083596, 13 pages, 2018.

[45] P. M. Henson and D. L. Bratton, "Antiinflammatory effects of apoptotic cells," The Journal of Clinical Investigation, vol. 123, no. 7, pp. 2773-2774, 2013.

[46] M. A. Sugimoto, L. P. Sousa, V. Pinho, M. Perretti, and M. M. Teixeira, "Resolution of inflammation: what controls its onset?," Frontiers in Immunology, vol. 7, pp. 160-178, 2016.

[47] G.-J. Wang, Y. Wang, Y.-S. Teng et al., "Protective effects of Emodin-induced neutrophil apoptosis via the $\mathrm{Ca}^{2+}$-caspase 12 pathway against SIRS in rats with severe acute pancreatitis," BioMed Research International, vol. 2016, Article ID 1736024, 9 pages, 2016.

[48] A. Byrne and D. J. Reen, "Lipopolysaccharide induces rapid production of IL-10 by monocytes in the presence of apoptotic neutrophils," The Journal of Immunology, vol. 168, no. 4, pp. 1968-1977, 2002.

[49] C. D. Gregory and A. Devitt, "The macrophage and the apoptotic cell: an innate immune interaction viewed simplistically?," Immunology, vol. 113, no. 1, pp. 1-14, 2004. 


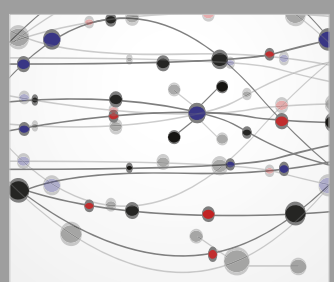

The Scientific World Journal
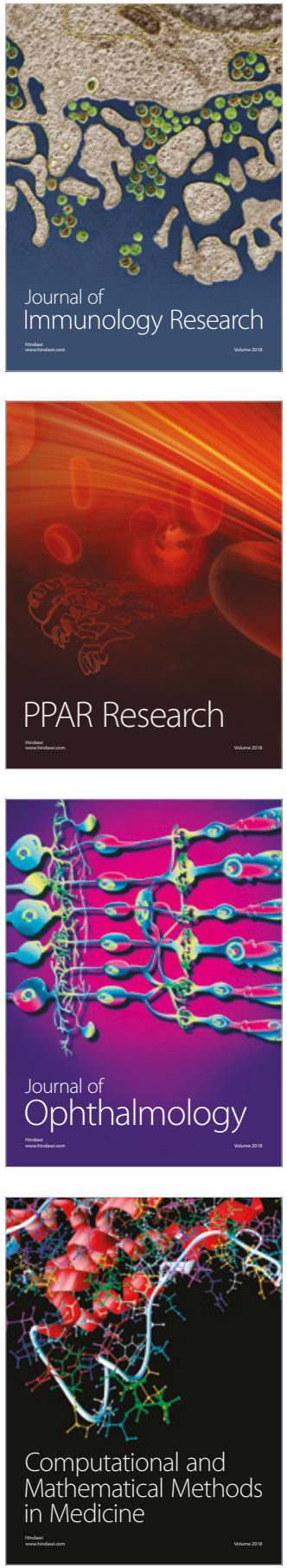

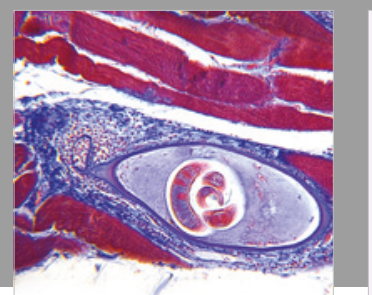

Gastroenterology Research and Practice

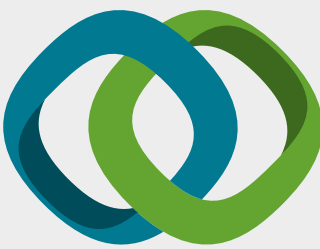

\section{Hindawi}

Submit your manuscripts at

www.hindawi.com
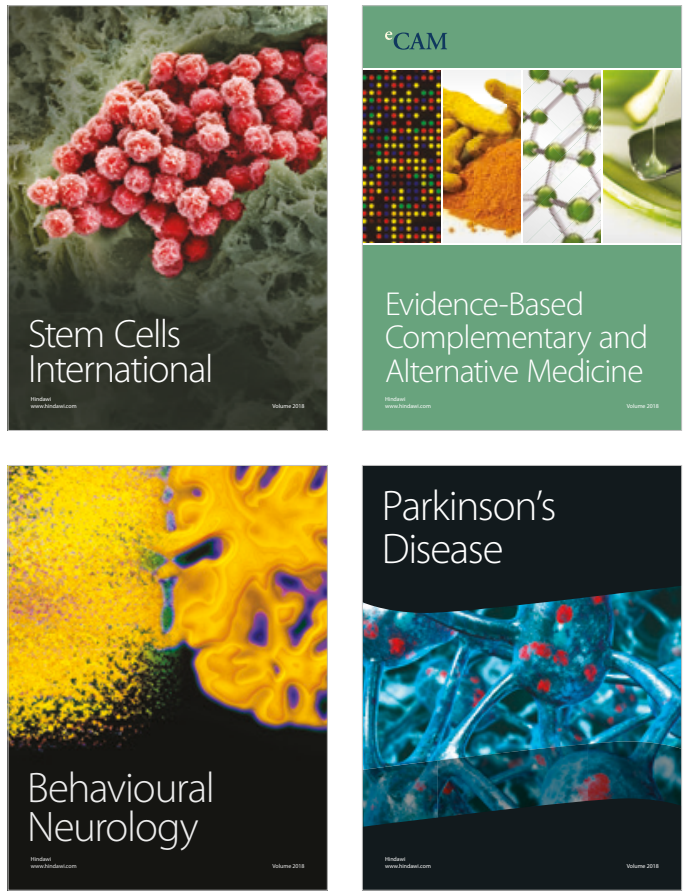

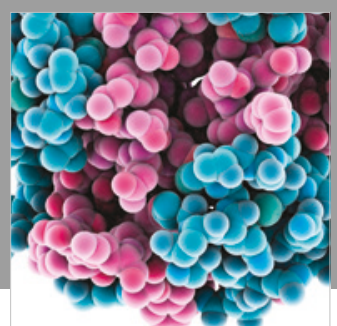

ournal of

Diabetes Research

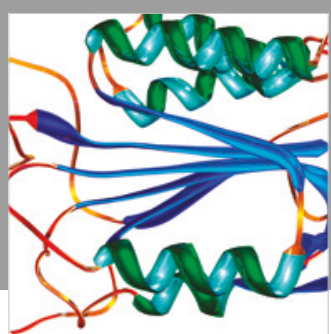

Disease Markers
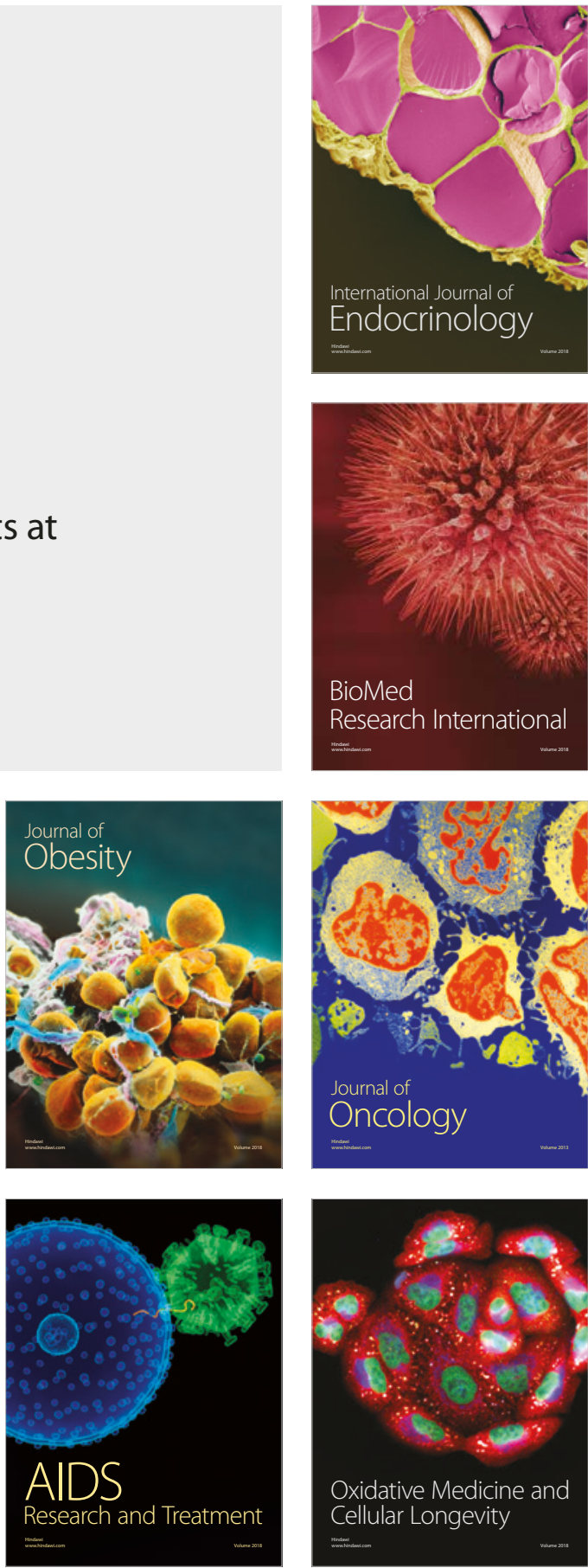